\title{
UM ESTUDO SOBRE PREVISÃO DA DEMANDA DE ENCOMENDAS UTILIZANDO UMA REDE NEURAL ARTIFICIAL
}

\author{
Arthur Ferreira \\ Universidade de São Paulo - USP - São Paulo - Brasil \\ arthur2.ferreira@usp.br \\ Ricardo Pinto Ferreira \\ Universidade Nove de Julho - São Paulo - Brasil \\ kasparov@uninove.edu.br \\ Andréa Martiniano da Silva \\ Universidade Nove de Julho - São Paulo - Brasil \\ martin@uninove.edu.br \\ Aleister Ferreira \\ Faculdade Santa Rita de Cássia - São Paulo - Brasil \\ aleisterferreira@hotmail.com \\ Renato José Sassi \\ Universidade Nove de Julho - São Paulo - Brasil \\ sassi@uninove.br
}

Resumo

Nas últimas décadas, o Brasil passou por diversas transformações, passando de uma economia fechada para uma economia de mercado. Ao transporte, tratamento e distribuição de encomendas restaram acompanhar essas tendências. Em razão disso, o serviço de entrega de encomendas tornou-se altamente complexo e competitivo. Nesse contexto, a previsão da demanda de encomendas surge como diferencial, levando produtividade estruturada e alto nível de serviço ao cliente. O objetivo do artigo é prever a demanda diária de encomendas em um Centro de Tratamento de Encomendas (CTE), durante quinze dias, utilizando Redes Neurais Artificiais (RNAs). A síntese metodológica do artigo consiste no desenvolvimento de uma Rede Neural Artificial do tipo Multilayer Perceptron (MLP), treinada através do algoritmo de error back-propagation. Os dados para a realização dos experimentos foram coletados durante 60 dias úteis, 45 dias para treinamento e 15 dias para teste. Os resultados obtidos com a utilização das RNAs na previsão da demanda de encomendas apresentaram boa aderência aos dados experimentais nas fases de treinamento e teste.

Palavras-chave: Previsão da demanda; Encomendas; Redes Neurais Artificiais.

\begin{abstract}
In recent decades, Brazil has undergone several transformations, from a closed economy to a market economy. Transport, processing and distribution of orders remained follow these trends. As a result, the delivery parcel service has become highly complex and competitive. In this context, the forecast demand of orders comes as differential, leading structured productivity and high level of customer service. The paper aims to provide for the daily demand of orders in a Orders Treatment Centre (ETC) for fifteen days using Artificial Neural Networks (ANN). The methodological synthesis of the article is the development of a Neural Network Multilayer Perceptron Artificial (MLP), trained by back-propagation algorithm error. The data for the experiments were collected for 60 days, 45 days to training and 15 days for testing. The results obtained with the use of ANNs in demand forecast orders showed good adhesion to the experimental data in the training and testing phases.
\end{abstract}

Keywords. Demand forecasting; orders; Artificial Neural Networks. 


\section{Introdução}

O ambiente logístico de transporte, tratamento e distribuição de encomendas sofre modificações constantes em decorrência de mudanças nos mercados nas condutas de concorrentes nos fornecedores e na tecnologia utilizada. Para articular ou aprimorar uma estratégia empresarial que responda a este ambiente em transformação, é necessária uma metodologia de planejamento e de projeto que considere fatores relevantes e avalie alternativas de forma eficiente [1].

Os novos hábitos de consumo dos brasileiros trouxeram ao mercado produtos com ciclo de vida mais curto e, consequentemente, volumes crescentes de itens coletados ou distribuídos todos os dias [2].

Ao transporte, tratamento e distribuição de encomendas restaram acompanhar essas tendências. Em razão disso, o serviço de entrega de encomendas tornou-se altamente complexo e competitivo.

De acordo com [3], existem várias técnicas de previsão de demandas disponíveis, entre elas está o método das Redes Neurais Artificiais, utilizado neste artigo. São modelos matemáticos de previsão inspirados no funcionamento dos neurônios biológicos. Caracterizados por sua capacidade de aprender à medida que chegam novos dados. $\mathrm{O}$ grau de exatidão da previsão parece ser melhor do que em outros métodos de séries de tempo quando a série de tempo é descontínua.

Nesse contexto, a previsão da demanda de encomendas surge como diferencial, levando produtividade estruturada e alto nível de serviço ao cliente. Assim, as técnicas da inteligência artificial, mais precisamente as Redes Neurais Artificiais surgem como alternativa para a previsão da demanda de encomendas.

O artigo está organizado após essa seção introdutória da seguinte forma: na seção 2 são apresentados os conceitos básicos da Previsão da Demanda de Encomendas. Na seção 3 são apresentadas as Redes Neurais Artificiais, a Multilayer Perceptron, o Algoritmo de Treinamento da Rede Neural Artificial do tipo MLP e os Critérios de Parada de Treinamento da MLP. Na seção 4 é apresentada a Metodologia do artigo. Descrevem-se na seção 5 os Resultados dos experimentos. O trabalho é encerrado na seção 6 com as Considerações finais.

\section{PREVISÃO DA DEMANDA DE ENCOMENDAS}

O planejamento e o controle das atividades da cadeia de suprimentos/logística dependem de estimativas acuradas dos volumes de produtos e serviços a serem processados pela cadeia de suprimentos. Tais estimativas ocorrem tipicamente na forma de planejamentos e previsões [3].

De acordo com [4], a necessidade de reduzir custos, ao mesmo tempo elevar níveis de serviços, continuará a crescer. Muitas empresas começaram a examinar suas cadeias de abastecimento e sua rede de distribuição como uma das poucas áreas remanescentes onde podem reduzir custos. O Centro de Tratamento de Encomendas evolui para atender às pressões contínuas de redução de custo, aliada as mudanças das necessidades do cliente será um elemento crítico na capacitação das empresas para competir com sucesso.

Destaca ainda [3] que, quando a incerteza da variável é tão alta que as técnicas mais comuns de previsão e suas utilizações no planejamento da cadeia de suprimentos levam a resultados insatisfatórios, surge a necessidade de outras modalidades de previsão.

A previsão de demanda é essencial para a empresa como um todo, à medida que proporciona a entrada básica para o planejamento e controle de todas as áreas funcionais, entre as quais Logística, Marketing, Produção e Finanças. Os níveis de demanda e os momentos em que ocorrem afetam fundamentalmente os índices de capacidade, as necessidades financeiras e a estrutura geral de qualquer negócio. Cada uma das áreas 
funcionais tem problemas específicos de previsão. A previsão de demanda abrange tanto a natureza espacial quanto a natureza temporal da demanda, a extensão de sua viabilidade e seu grau de aleatoriedade [3].

Para [5], prover a capacidade produtiva para satisfazer à demanda atual e futura é uma responsabilidade fundamental da administração de produção. Obtenha o equilíbrio adequado entre capacidade e demanda e satisfará os clientes de forma eficaz em custo. Obtendo o equilíbrio errado, deixará de atender à demanda e terá custos excessivos.

Embora a previsão de demanda seja geralmente responsabilidade dos departamentos de vendas e/ou marketing, é um insumo muito importante para a decisão do planejamento e controle de capacidade, normalmente uma responsabilidade da gerência de produção. Afinal, sem uma previsão de demanda não é possível planejar efetivamente para futuros eventos, somente reagir a eles. Por isso é importante que os tomadores de decisão entendam a base e os fundamentos logísticos para essas previsões de demanda.

\section{REDES NEURAIS ARTIFICIAS}

As Redes Neurais Artificiais são modelos constituídos por unidades de processamento simples, chamados de neurônios artificiais, que calculam funções matemáticas. Estes modelos são inspirados na estrutura do cérebro e têm como objetivo simular o comportamento humano, tais como: aprendizagem, associação, generalização e abstração quando submetidas a treinamento.

De acordo com [6] as RNAs são particularmente eficientes para o mapeamento entrada/saída de sistemas não lineares e para realizar processamento paralelo, além de simular sistemas complexos. As RNAs generalizam os resultados obtidos para dados previamente desconhecidos, ou seja, produzem respostas coerentes e apropriadas para padrões ou exemplos que não foram utilizados no seu treinamento.

As RNAs podem ser aplicadas em diversas áreas e na solução de vários problemas como: reconhecimento de padrões [6], descoberta de conhecimento em bases de dados [7], medicina [8], previsão de risco de crédito [9], indústria automotiva [10], previsão do comportamento do tráfego veicular urbano [11], e para identificar empregados absenteístas e presenteístas [12] entre outros.

\subsection{A MULTILAYER PERCEPTRON (MLP)}

Uma RNA do tipo MLP consiste de um conjunto de unidades (nós ou neurônios), que constituem a camada de entrada, uma ou mais camadas ocultas e uma camada de saída, onde o sinal de entrada se propaga pela RNA camada por camada. Na Figura 1 é apresentada a estrutura básica de uma RNA do tipo MLP.

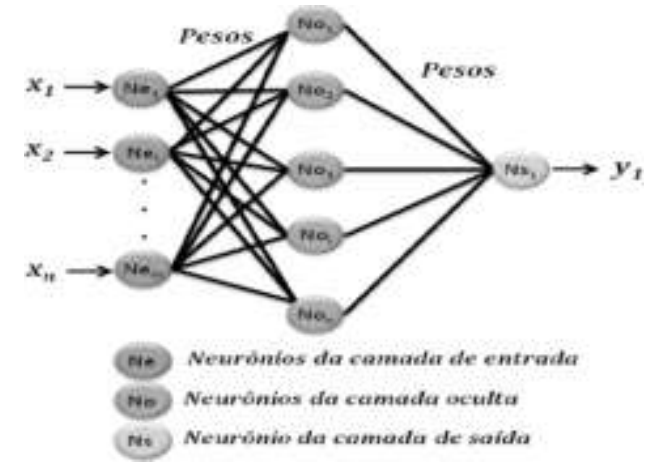

FIGURA 1 - Estrutura básica da RNA do tipo MLP. Fonte: Adaptado de [7].

Observa-se na Figura 1 os dados (vetores de dados) de entrada da rede $(\mathrm{X} 1, \ldots, \mathrm{XN})$, os neurônios da camada de entrada da rede $(\mathrm{Ne} 1, \ldots, \mathrm{Nem})$ com seus respectivos pesos, os neurônios que formam a camada intermediária da rede (No1,..., Non) e a camada de saída (Ns1), formada por um neurônio. 
A rede MLP normalmente é aplicada em problemas de classificação [13], de aproximação (ou análise de regressão) que inclui previsão e modelagem de séries temporais [6] em áreas como: controle [14], diagnóstico [15] e data mining [16].

\subsection{ALGORITMO DE TREINAMENTO DA REDE NEURAL ARTIFICIAL DO TIPO MLP}

As RNAs possuem a capacidade de aprender por exemplos e fazer interpolações e extrapolações do que aprenderam. Um conjunto de procedimentos bem definidos, para adaptar os pesos de uma RNA para que ela possa aprender uma determinada função, é chamado algoritmo de treinamento ou de aprendizado [16].

O aprendizado de uma RNA usa um conjunto de dados correspondentes a uma amostra de sinais para entrada e saída do sistema. Para esse treinamento, a rede utiliza algoritmos de aprendizado.

Inicialmente a rede permanece inerte e o algoritmo de aprendizado modifica individualmente os pesos das interconexões de tal forma que o comportamento da rede reflita a ação desejada. Em outras palavras, a rede pode alterar sua estrutura interna de maneira incremental até que se alcance o desempenho esperado de estimação dos dados [17].

Como resultado do treinamento, a RNA produzirá valores de saída similares ao conjunto de dados para valores que sejam iguais às amostras de treinamento. Para valores intermediários, a rede produzirá uma interpolação. Ou seja, as RNAs podem aprender através de exemplos [17].

O algoritmo de retroprogramação do erro (error back-propagation), utilizado na MLP, consiste, basicamente, em determinar as variações nos pesos sinápticos da RNA, tendo como objetivo minimizar o erro obtido na saída através do aprendizado do vetor de treinamento (entradasaída) [18].

Para isso, o algoritmo baseia-se no método do gradiente descendente, o qual, dada uma medida do erro, procura modificar o conjunto de pesos wij da rede, reduzindo o erro na direção mais íngreme da superfície definida no espaço $w$ [6].

Em resumo, o algoritmo do gradiente descendente estabelece mudanças nos pesos wij por uma quantidade $\Delta w j$ proporcional ao gradiente do erro.

O algoritmo de retroprogramação do erro (error back-propagation) funciona da seguinte forma: apresenta-se um padrão à camada de entrada da rede, esse padrão é processado camada por camada até que a camada de saída forneça a resposta processada, $f_{M L P}$, como mostra a Equação (1):

$$
f_{M L P}(x)=\varphi\left(\sum_{1}^{N o n} v_{l} \cdot \varphi\left(\sum w_{l j} x_{l}+b_{l 0}\right)+b_{0}\right)
$$

onde $v l$ e $w$ lj são pesos sinápticos; $b 10$ e $b 0$ são os biases; e $\varphi$ a função de ativação, comumente especificada como sendo a função sigmóide. A Figura 2 mostra a função sigmóide.

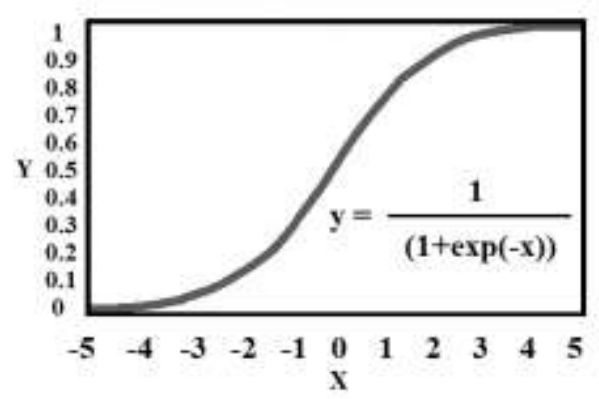

FIGURA 2 - Função sigmóide. Fonte: Adaptado de [19] 
O princípio deste algoritmo, para cálculo dos erros nas camadas intermediárias, é o seu cálculo por retroalimentação, possibilitando, desta forma, o ajuste dos pesos proporcionalmente aos valores das conexões entre camadas. De acordo com [6], a MLP possui as seguintes características: função de ativação não-linear (sigmoidal), uma ou mais camadas de neurônios ocultos e um alto grau de conectividade. Uma RNA MLP treinada com o algoritmo de retropropagação realiza um mapeamento não linear de entrada-saída.

\subsection{CRITÉRIOS DE PARADA DE TREINAMENTO DA MLP}

De acordo com Simões e Shaw [17], em um processo iterativo como o algoritmo error backpropagation, uma questão importante é sobre o critério de parada do treinamento.

Em termos absolutos, a solução final ocorrerá para o índice de desempenho (erro global) igual a zero ou dentro de um valor muito pequeno. Contudo, se durante a fase de treinamento o erro não for pequeno e não tiver tendência a diminuir, dois enfoques podem ser adotados:

a) Limitar o número de iterações, ou seja, o treinamento cessa após ter ocorrido um valor limite, prefixado, de épocas de treinamento.

b) Amostrar e tirar a média de certo número de épocas, por exemplo, 500 épocas. Se o erro médio do último conjunto de 500 épocas não for melhor que o das 500 anteriores o treinamento dever ser cessado, indicando que um mínimo local foi alcançado. Depois disso, a rede deve estar ainda pronta para ser reutilizada para testes.

\section{METODOLOGIA}

A metodologia do artigo consiste no desenvolvimento de RNAs do tipo Multilayer Perceptron, treinadas através do algoritmo de error back-propagation. Os dados foram coletados numa empresa de grande porte durante 60 dias úteis, 45 dias para treinamento e 15 dias para teste. Os parâmetros utilizados para o desenvolvimento da RNA no experimento 1 foram: número de neurônios de entrada igual a 12 , número de camadas ocultas igual a 2 , número de neurônios nas camadas ocultas igual a 5, taxa de aprendizagem constante igual a 0,3, fator de momento constante igual 0,5 , critério de parada erro igual 0,01 e número máximo de iterações ou épocas igual a 200. As doze entradas da RNA foram: semana do mês (primeira semana, segunda, terceira ou quarta semana); dia da semana (segunda a sexta-feira); encomendas urgentes; não urgentes; tipo de carga (três tipos A, B, C); encomendas do setor fiscal; encomendas do setor controlador de trânsito e três entradas com clientes do setor financeiro. A saída da RNA é a previsão da demanda de encomendas por dia. A Figura 3 mostra a arquitetura da RNA do tipo MLP utilizada no experimento 1.

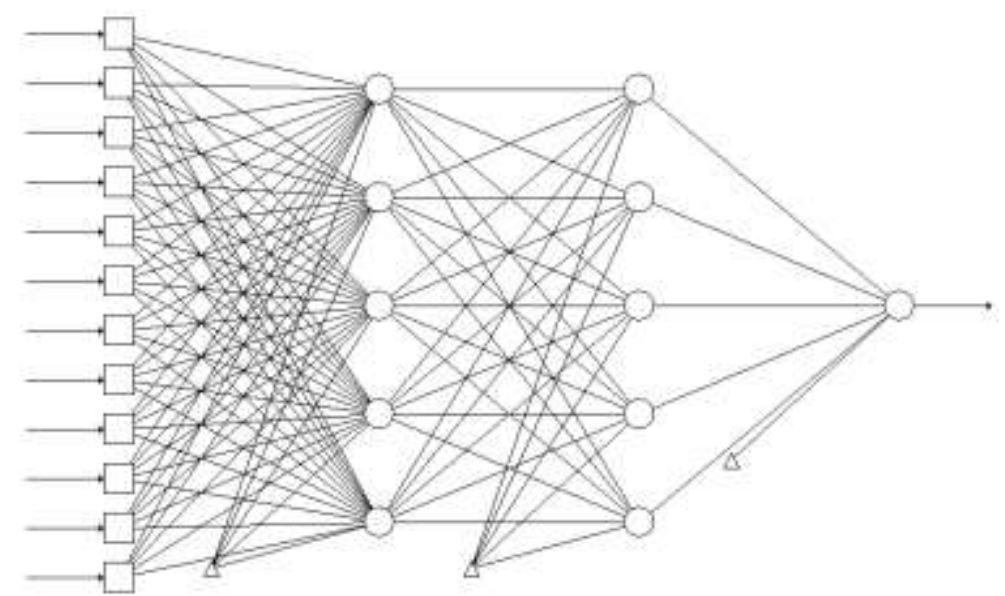

FIGURA 3 - Arquitetura da RNA do tipo MLP. 
A Tabela 1 apresenta os parâmetros utilizados nos quatro experimentos realizados. TABELA 1 - Parâmetros utilizados na RNA do tipo MLP

\begin{tabular}{|c|c|c|c|c|c|c|c|c|}
\hline Experimento & $\begin{array}{l}\text { Dados de Treinamento } \\
\text { (Em das) }\end{array}$ & $\begin{array}{l}\text { Dados de teste } \\
\text { (Em dias) }\end{array}$ & $\begin{array}{c}\text { Número } \\
\text { de } \\
\text { neurónios } \\
\text { de entrada }\end{array}$ & $\begin{array}{l}\text { Camadas } \\
\text { ocuiltas }\end{array}$ & $\begin{array}{c}\text { Número de } \\
\text { neurónios nas } \\
\text { camadas ocultas }\end{array}$ & $\begin{array}{c}\text { Taxa de } \\
\text { aprendizagem }\end{array}$ & $\begin{array}{c}\text { Taxa de } \\
\text { momentum }\end{array}$ & $\begin{array}{c}\text { Critério de } \\
\text { parada da RNA }\end{array}$ \\
\hline Experimento 01 & 45 & 15 & 12 & 2 & 5 & 0,3 & 0,5 & $\begin{array}{c}\text { Erro menor que } \\
0,01 \text { ou } 200 \\
\text { epocas }\end{array}$ \\
\hline Experimento 02 & 45 & 15 & 12 & 2 & 7 & 0,5 & 0,7 & $\begin{array}{c}\text { Erro menor que } \\
0,01 \text { ou } 200 \\
\text { épocas }\end{array}$ \\
\hline Experimento 03 & 45 & 15 & 12 & 2 & 10 & 0,7 & 0,7 & $\begin{array}{c}\text { Erro menor que } \\
0,01 \text { ou } 150 \\
\text { épocas }\end{array}$ \\
\hline Experimento 04 & 45 & 15 & 12 & 3 & 5 & 0,5 & 0,9 & $\begin{array}{c}\text { Erro menor que } \\
0,01 \text { ou } 100 \\
\text { épocas }\end{array}$ \\
\hline
\end{tabular}

\section{RESULTADO DOS EXPERIMENTOS}

Uma vez apresentado nas seções anteriores a metodologia do artigo e os conceitos básicos de previsão de demanda e das Redes Neurais Artificiais, nesta seção serão apresentados os resultados dos experimentos. A Figura 4 mostra a fase de treinamento da rede neural artificial (dados reais e saída da RNA). Experimento 1. O eixo x corresponde aos dias de treinamento, o eixo y corresponde à quantidade de encomendas.

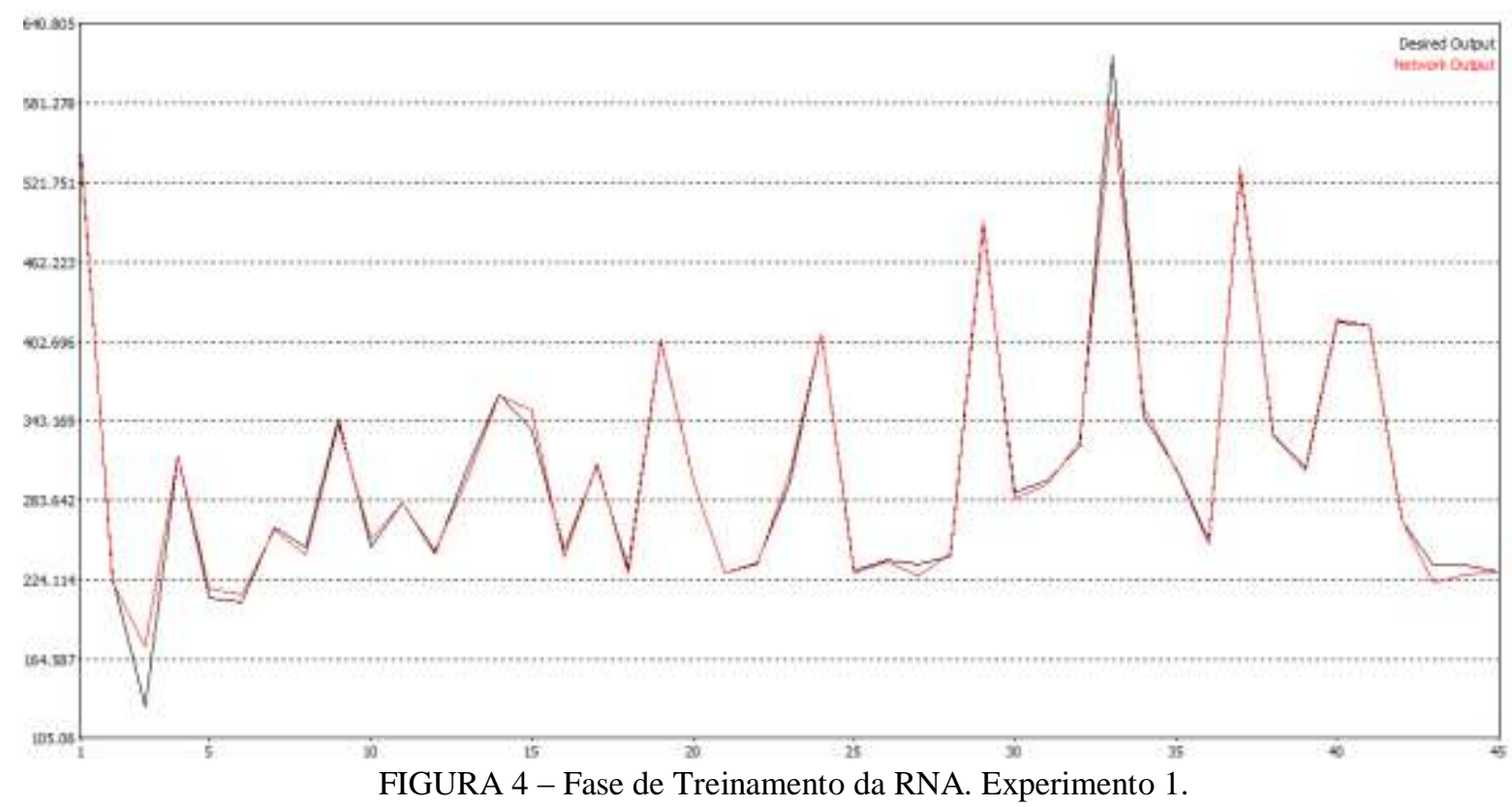

A Figura 5 mostra a fase de teste da rede neural artificial (dados reais e saída da RNA), referente ao período de previsão. Experimento 1. 


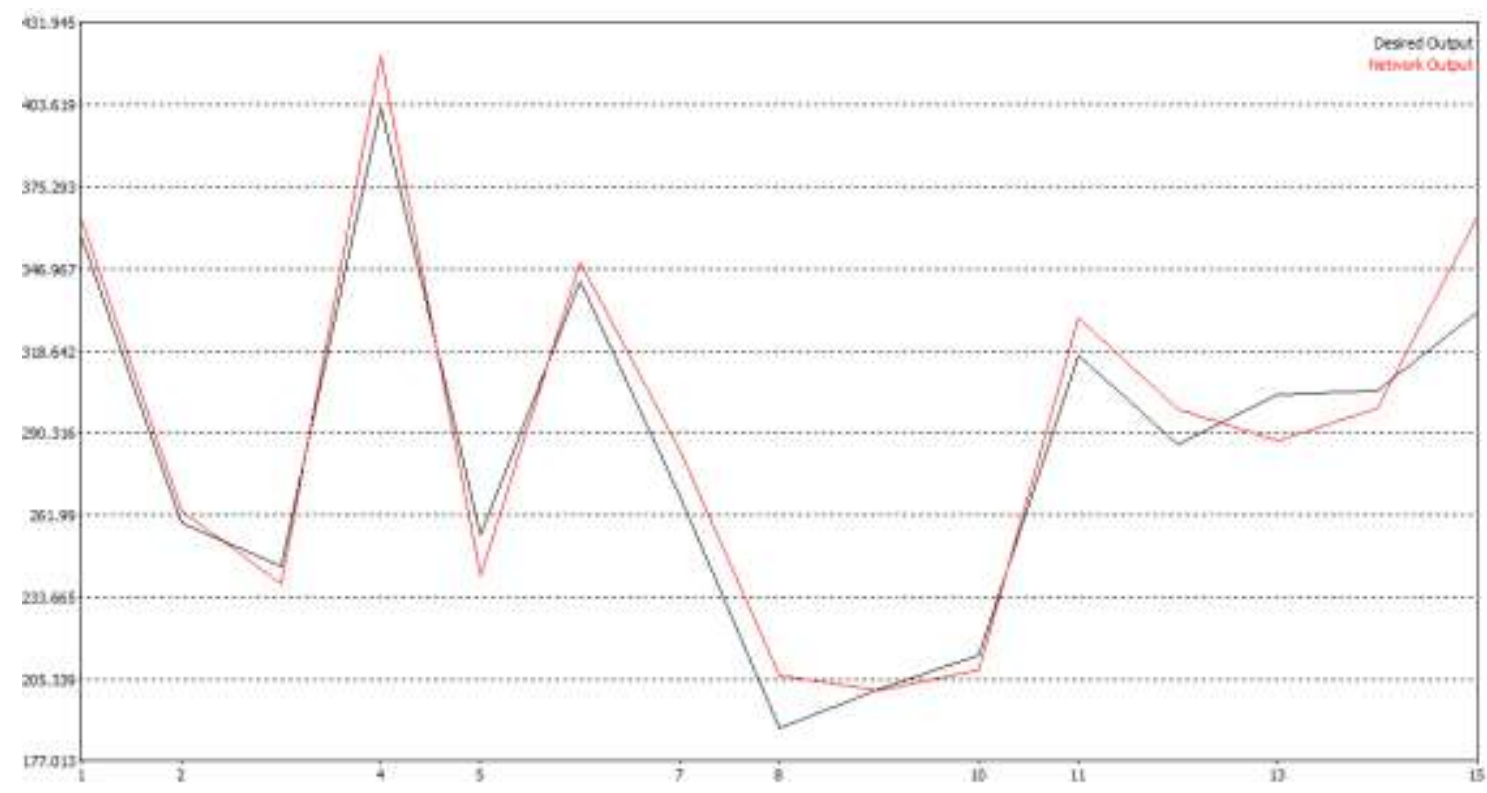

FIGURA 5 - Fase de Teste da RNA. Experimento 1.

A Figura 6 mostra a fase de treinamento da rede neural artificial (dados reais e saída da RNA). Experimento 2.

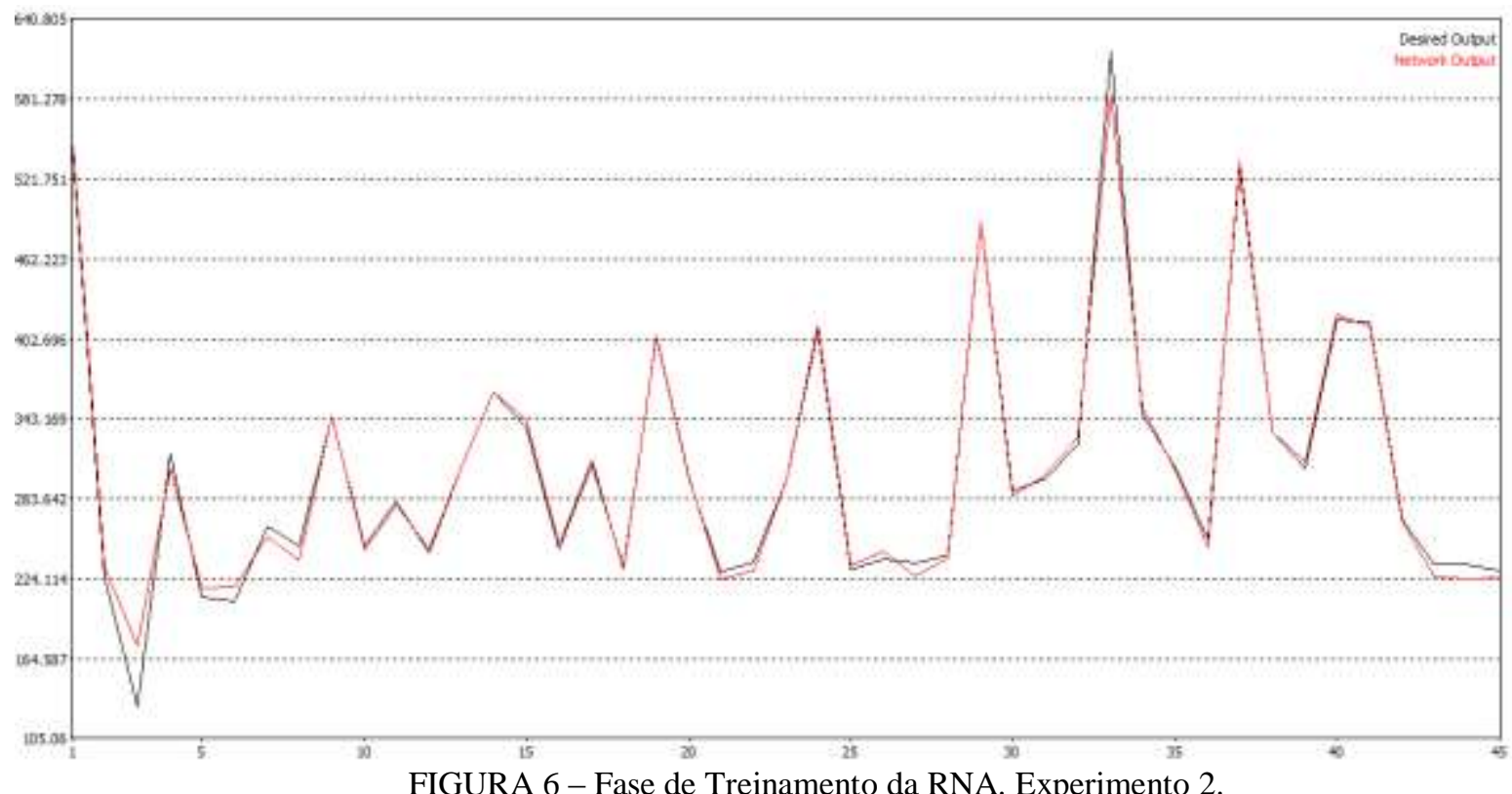

FIGURA 6 - Fase de Treinamento da RNA. Experimento 2.

A Figura 7 mostra a fase de teste da rede neural artificial (dados reais e saída da RNA), referente ao período de previsão. Experimento 2. 


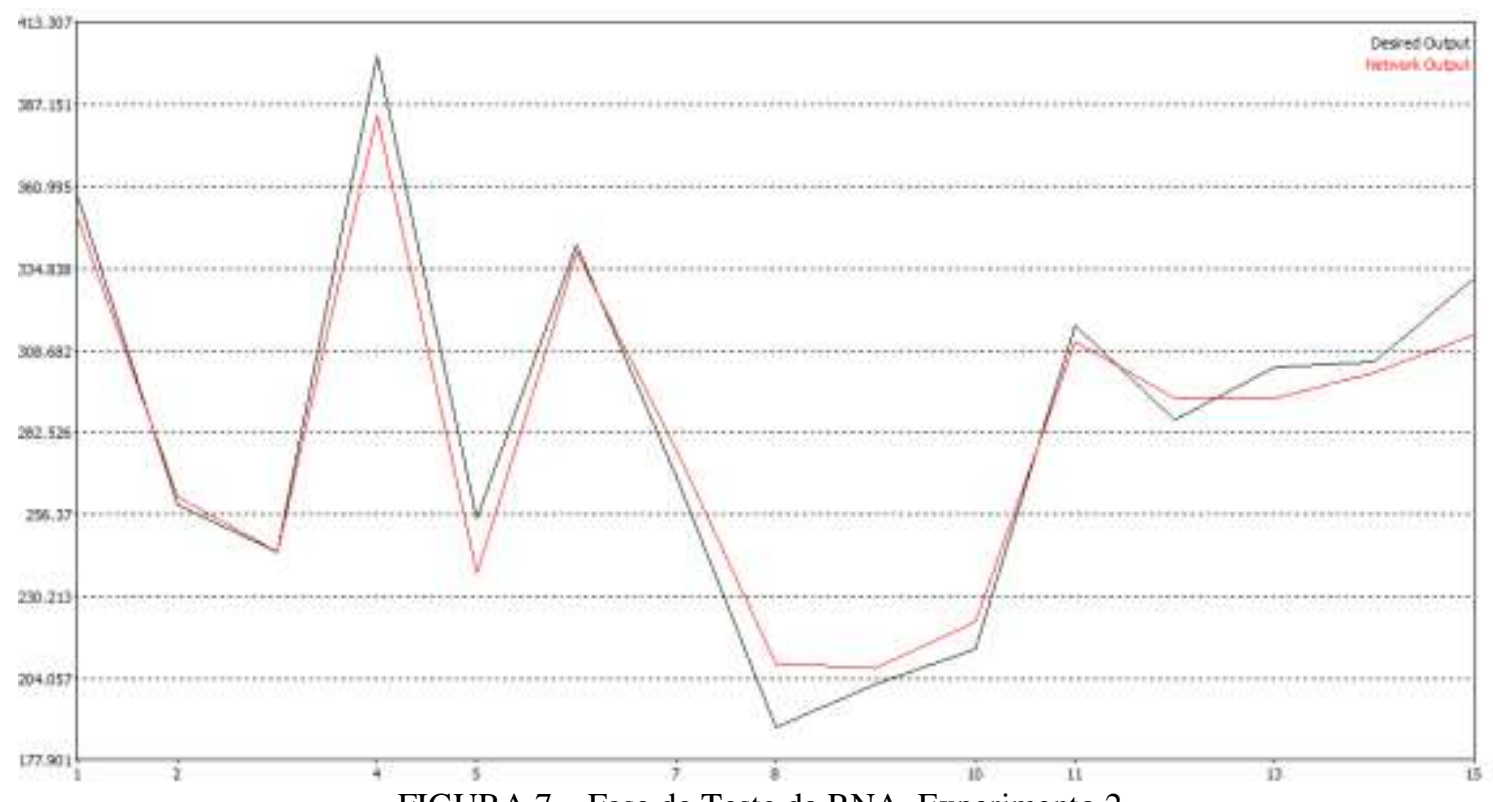

FIGURA 7 - Fase de Teste da RNA. Experimento 2.

A Figura 8 mostra a fase de treinamento da rede neural artificial (dados reais e saída da RNA). Experimento 3.

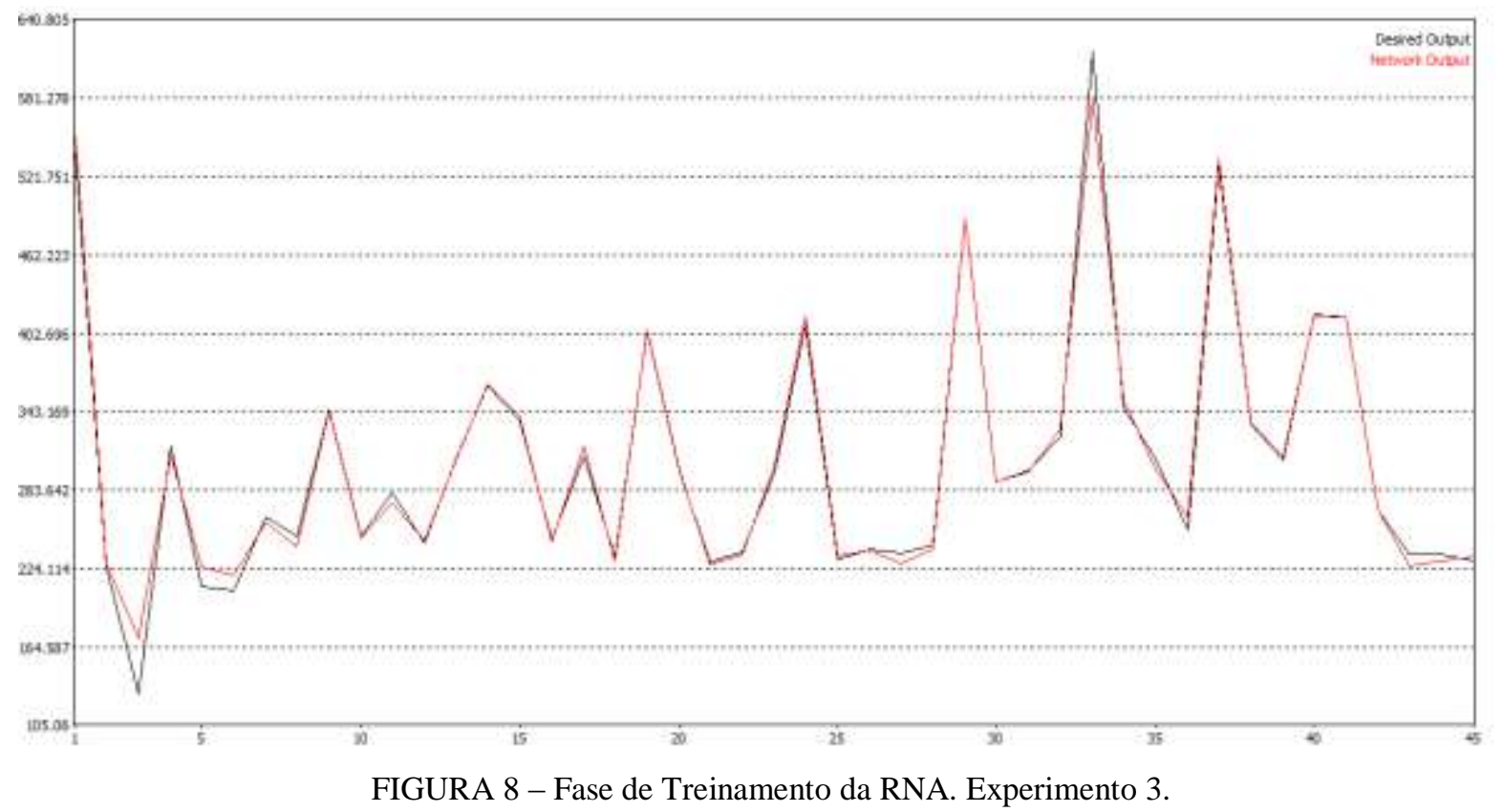

A Figura 9 mostra a fase de teste da rede neural artificial (dados reais e saída da RNA), referente ao período de previsão. Experimento 3. 


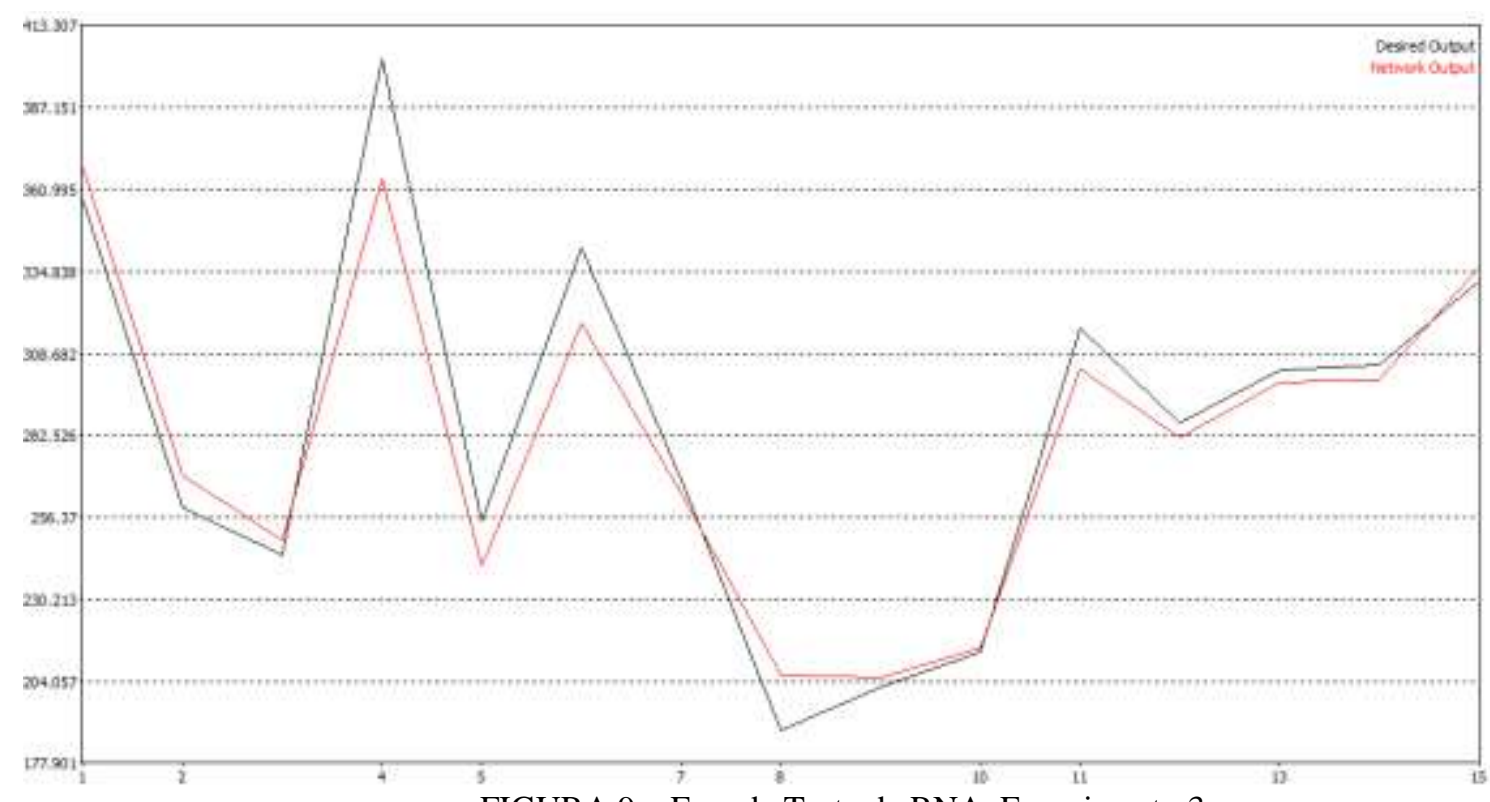

FIGURA 9 - Fase de Teste da RNA. Experimento 3.

A Figura 10 mostra a fase de treinamento da rede neural artificial (dados reais e saída da RNA). Experimento 4.

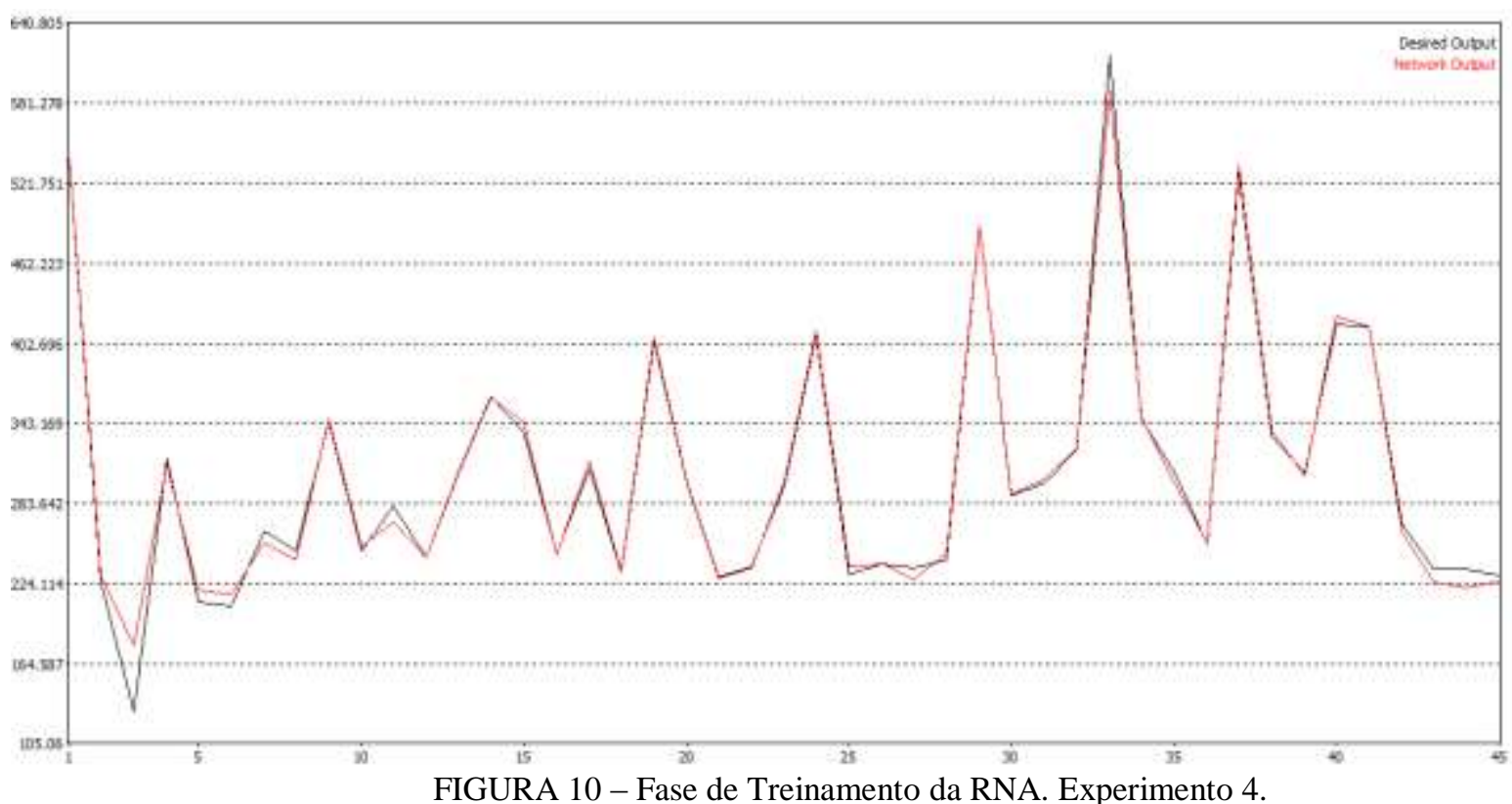

A Figura 11 mostra a fase de teste da rede neural artificial (dados reais e saída da RNA), referente ao período de previsão. Experimento 4. 


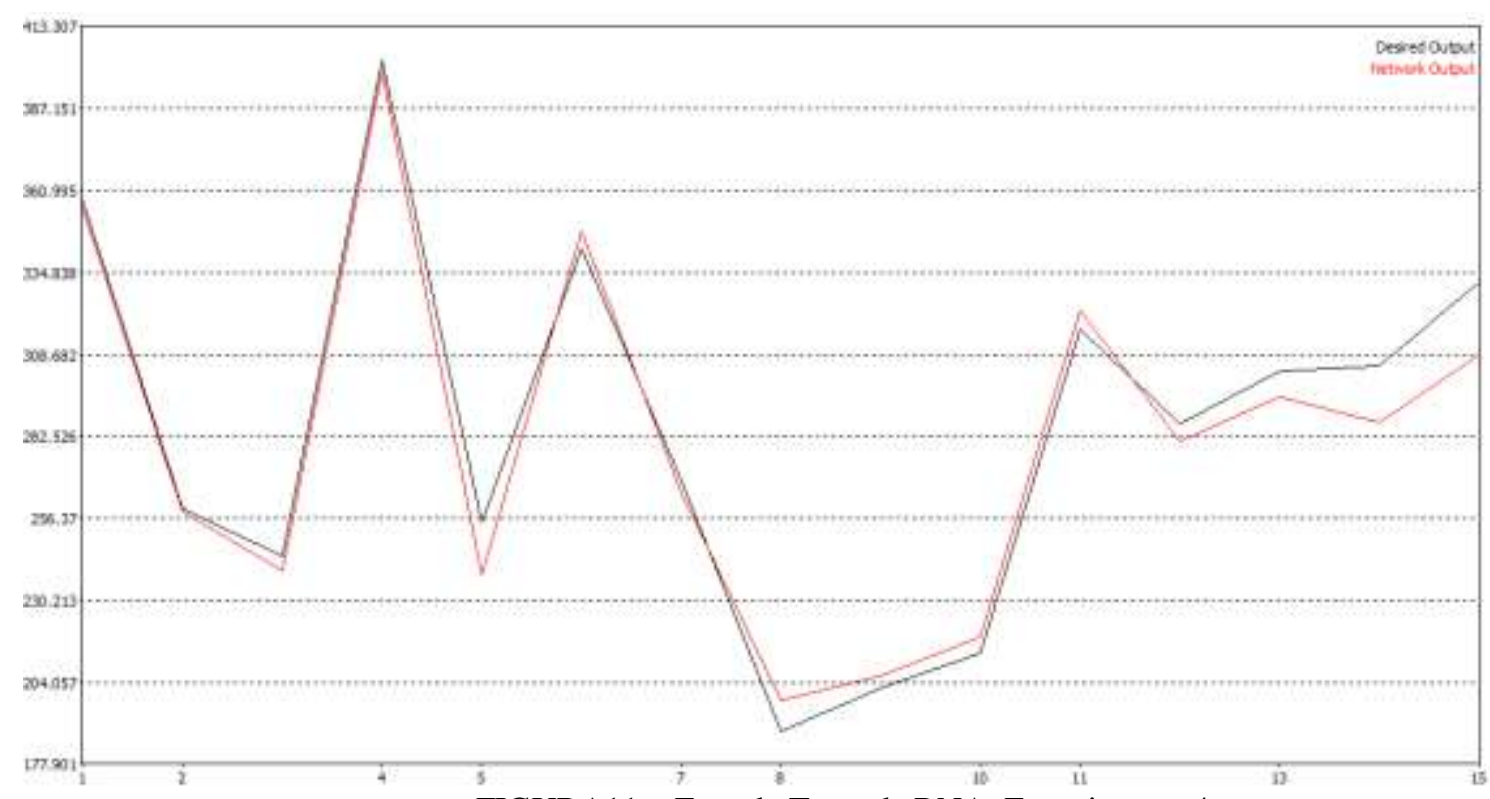

FIGURA11 - Fase de Teste da RNA. Experimento 4.

O Quadro 1 apresentam os resultados dos experimentos 1 e 2.

QUADRO 1 - Experimentos 1 e 2

\begin{tabular}{|c|c|c|c|c|c|c|c|}
\hline $\begin{array}{c}\text { Experimento 1 } \\
\text { Saída desejada }\end{array}$ & $\begin{array}{c}\text { Saída da } \\
\text { RNA }\end{array}$ & Erro & Erro (\%) & $\begin{array}{c}\text { Experimento } 2 \\
\text { Saída desejada }\end{array}$ & Saída da RNA & Erro & Erro (\%) \\
\hline 357394 & 363820 & -6.426 & $1,80 \%$ & 357394 & 350884 & 6.510 & $-1,82 \%$ \\
\hline 259246 & 263467 & -4.221 & $1,63 \%$ & 259246 & 262099 & -2.853 & $1,10 \%$ \\
\hline 244235 & 238234 & 6.001 & $-2,46 \%$ & 244235 & 244316 & -81 & $0,03 \%$ \\
\hline 402607 & 420356 & -17.749 & $4,41 \%$ & 402607 & 383946 & 18.661 & $-4,64 \%$ \\
\hline 255061 & 241088 & 13.973 & $-5,48 \%$ & 255061 & 237569 & 17.492 & $-6,86 \%$ \\
\hline 342606 & 349398 & -6.792 & $1,98 \%$ & 342606 & 339828 & 2.778 & $-0,81 \%$ \\
\hline 268640 & 284392 & -15.752 & $5,86 \%$ & 268640 & 277184 & -8.544 & $3,18 \%$ \\
\hline 188601 & 206413 & -17.812 & $9,44 \%$ & 188601 & 208709 & -20.108 & $10,66 \%$ \\
\hline 202022 & 201645 & 377 & $-0,19 \%$ & 202022 & 207233 & -5.211 & $2,58 \%$ \\
\hline 213509 & 208241 & 5.268 & $-2,47 \%$ & 213509 & 221871 & -8.362 & $3,92 \%$ \\
\hline 316849 & 330183 & -13.334 & $4,21 \%$ & 316849 & 311335 & 5.514 & $-1,74 \%$ \\
\hline 286412 & 298236 & -11.824 & $4,13 \%$ & 286412 & 293366 & -6.954 & $2,43 \%$ \\
\hline 303447 & 287562 & 15.885 & $-5,23 \%$ & 303447 & 293479 & 9.968 & $-3,28 \%$ \\
\hline 304950 & 298795 & 6.155 & $-2,02 \%$ & 304950 & 301712 & 3.238 & $-1,06 \%$ \\
\hline 331900 & 364577 & -32.677 & $9,85 \%$ & 331900 & 313555 & 18.345 & $-5,53 \%$ \\
\hline
\end{tabular}

Observa-se no experimento 1 que os maiores erros são de 9,44\% e 9,85\%. No experimento 2 o maior erro é de 10,66\%. Os demais resultados apresentam erros menores. 
O Quadro 2 apresentam os resultados dos experimentos 3 e 4.

QUADRO 2 - Experimentos 3 e 4

\begin{tabular}{|c|c|c|c|c|c|c|c|}
\hline $\begin{array}{l}\text { Experimento } 3 \\
\text { Saída desejada }\end{array}$ & $\begin{array}{l}\text { Saída da } \\
\text { RNA }\end{array}$ & Erro & Erro (\%) & $\begin{array}{l}\text { Experimento } 4 \\
\text { Saída desejada }\end{array}$ & Saída da RNA & Erro & Erro (\%) \\
\hline 357394 & 368063 & -10669 & $2,99 \%$ & 357394 & 354985 & 2409 & $-0,67 \%$ \\
\hline 259246 & 269817 & -10571 & $4,08 \%$ & 259246 & 258795 & 451 & $-0,17 \%$ \\
\hline 244235 & 249214 & -4979 & $2,04 \%$ & 244235 & 239476 & 4759 & $-1,95 \%$ \\
\hline 402607 & 364619 & 37988 & $-9,44 \%$ & 402607 & 398959 & 3648 & $-0,91 \%$ \\
\hline 255061 & 240887 & 14174 & $-5,56 \%$ & 255061 & 238451 & 16610 & $-6,51 \%$ \\
\hline 342606 & 318292 & 24314 & $-7,10 \%$ & 342606 & 348095 & -5489 & $1,60 \%$ \\
\hline 268640 & 264040 & 4600 & $-1,71 \%$ & 268640 & 264455 & 4185 & $-1,56 \%$ \\
\hline 188601 & 206145 & -17544 & $9,30 \%$ & 188601 & 198491 & -9890 & $5,24 \%$ \\
\hline 202022 & 205087 & -3065 & $1,52 \%$ & 202022 & 206296 & -4274 & $2,12 \%$ \\
\hline 213509 & 214609 & -1100 & $0,52 \%$ & 213509 & 218679 & -5170 & $2,42 \%$ \\
\hline 316849 & 303630 & 13219 & $-4,17 \%$ & 316849 & 322827 & -5978 & $1,89 \%$ \\
\hline 286412 & 281644 & 4768 & $-1,66 \%$ & 286412 & 281091 & 5321 & $-1,86 \%$ \\
\hline 303447 & 299470 & 3977 & $-1,31 \%$ & 303447 & 295232 & 8215 & $-2,71 \%$ \\
\hline 304950 & 300418 & 4532 & $-1,49 \%$ & 304950 & 287164 & 17786 & $-5,83 \%$ \\
\hline 331900 & 336212 & -4312 & $1,30 \%$ & 331900 & 308548 & 23352 & $-7,04 \%$ \\
\hline
\end{tabular}

Observa-se no experimento 3 que os maiores erros são de 9,30\% e 9,44\%. No experimento 4 o maior erro é de 7,04\%. Os demais resultados apresentam erros menores.

Conclui-se que o experimento 4 apresentou o melhor resultado.

Observa-se nos resultados apresentados tanto na fase treinamento como na fase de teste que os quatro experimentos mostraram resultados satisfatórios, encorajando a realização de novos experimentos utilizando outras arquiteturas de RNAs e outras entradas, buscando melhorar o modelo proposto no artigo.

\section{CONSIDERAÇÕES FINAIS}

A RNA aplicada à previsão da demanda de encomendas apresentou boa aderência aos dados experimentais nas fases de treinamento e teste, pois a RNA identificou os padrões de comportamento num sistema complexo. A utilização das RNAs para a previsão da demanda em empresas de transporte, tratamento e distribuição de encomendas, permite adequar recursos produtivos conforme a demanda diária, evitando rupturas durante o processo de tratamento e perda de prazo de entrega, além de reduzir o custo com recursos disponibilizados desnecessariamente em operações mal dimensionadas por falta de previsão da demanda adequados. Pretende-se dar continuidade aos estudos com a realização de novos experimentos acrescentando outras entradas na RNA.

\section{REFERÊNCIAS BIBLIOGRÁFICAS}

[1] BOWERSOX, D. J.; CLOSS, D. J. Logística Empresarial: o processo de integração da cadeia de suprimento. Tradução de Equipe CEL e Adalberto Ferreira Neves. São Paulo: Atlas, 2010.

[2] TODAY Logistics \& Supply Chain. São Paulo: Cecilia Borges, Ano III, n. 38, 2009.

[3] BALlOU, R. H. Gerenciamento da Cadeia de Suprimentos/Logística Empresarial. Tradução de Raul Rubenich. 5. ed. Porto Alegre: Bookman, 2006. 
[4] BANZATO, E.; JUNIOR, E. C.; BANZATO, J. M.; MOURA, R. A.; RAGO, S. F. T. Atualidades na armazenagem. São Paulo: IMAM, 2008.

[5] SLACK, N.; CHAMBER, S.; HARDLAND, C.; HARRISON, A. e JOHNSTON, R. Administração da Produção. São Paulo: Atlas, 2009.

[6] HAYKIN, S. Redes Neurais - Princípios e Práticas. Bookman. 2a edição. Porto Alegre, 2001.

[7] SASSI, R. J. Uma Arquitetura Híbrida para Descoberta de Conhecimento em Bases de Dados: Teoria dos Rough Sets e Redes Neurais Artificiais Mapas Auto-Organizáveis. 169 p. Tese (Doutorado) - Escola Politécnica da Universidade de São Paulo, Departamento de Engenharia Elétrica, São Paulo, 2006.

[8] BLAZADONAKIS, E.; MICHALIS, Z. Support Vector Machines and Neural Networks as Marker Selectors in Cancer Gene Analysis. Intelligent Techniques and Tools for Novel System Architectures. Berlin, Heidelberg: Springer-Verlag Berlin Heidelberg, p. 237-258, 2008.

[9] SELAU, L. P. R.; RIBEIRO, J. L. D. Uma sistemática para construção e escolha de modelos de previsão de risco de crédito. Gestão Produção, São Carlos. v. 16, n. 3, p. 398-413, 2009.

[10] AFFONSO, C. Aplicação de Redes Neuro Fuzzy ao Processamento de Polímeros na Indústria Automotiva. 110 p. Dissertação (Mestradoem Engenharia de Produção) Universidade Nove de Julho, São Paulo, 2010.

[11] FERREIRA, R. P. Combinação de Técnicas da Inteligência Artificial para Previsão do Comportamento do Tráfego Veicular Urbano na Cidade de São Paulo. 107 p. Dissertação (Mestrado em Engenharia de Produção) - Universidade Nove de Julho - UNINOVE, São Paulo, 2011.

[12] MARTINIANO, A.; FERREIRA, R. P.; SASSI, R. J. Aplicação da Mineração de Dados na Identificação de Empregados Absenteístas e Presenteístas de uma Empresa de Courier da Cidade de São Paulo. VIII- EMEPRO, Encontro Mineiro de Engenharia de Produção. Itajubá, 2012.

[13] CARVAlHO, L. A. V. Data Mining: a Mineração de dados no Marketing, Medicina, Economia, Engenharia e Administração. Editora Ciência Moderna Ltda. Rio de Janeiro, 2005.

[14] MITCHELL, T. M. Machine Learning. McGraw-Hill, 1997.

[15] SILVA, L. A. Categorização de Imagens Médicas para Sistemas de Recuperação de Imagens por Conteúdo Baseada em Transformada Wavelet e Mapas Auto-Organizáveis. 99 p. Tese (Doutorado em Engenharia Elétrica) - Escola Politécnica da Universidade de São Paulo, 2009.

[16] BIGUS, J. P. Data Mining with Neural Network: Solving Business Problems from Applications Development to Decision Support. Mcgraw-Hill, 1996.

[17] SIMÕES, M. G.; SHAW, I. S. Controle e Modelagem fuzzy. São Paulo: Blucher: FAPESP, 2007.

[18] RUMELHART, D. E.; HINTON, G. E.; WILLIAMS, R. J. Learning Internal Representations by Error Propagation. In Parallel Distributed Processing: Explorations in the Microstructure of Cognition, Vol. 1: Foundations, D. E. Rumelhart and J. L. McClelland, Eds. Mit Press Computational Models Of Cognition And 12 Perception Series. MIT Press, Cambridge, MA, p. 318-362, 1986.

[19] SASSI, R. J.; SILVA, L. A.; HERNANDEZ, D. M. E. A Methodology using Neural Networks to Cluster Validity Discovered from a Marketing Database. In: 10th Brazilian Symposium on Neural Networks (SBRN), 2008, Salvador. IEEE Proceedings of SBRN. v. 1. p. 03-08, 2008. 